Permanent disappearance and seasonal fluctuation of urban lake area in Wuhan, China monitored with long time series remotely sensed images from 1987 to 2016

Lingfei Shi ${ }^{\mathrm{a}, \mathrm{b}, \mathrm{c}}$, Feng Ling ${ }^{\mathrm{a}}$, Giles M Foody ${ }^{\mathrm{c}}$, Cheng Chen ${ }^{\mathrm{d}}$, Shiming Fang ${ }^{\mathrm{e}}$, Xiaodong $\mathrm{Li}^{\mathrm{a}}{ }^{\mathrm{a}, \mathrm{c}}$, Yihang Zhang ${ }^{\mathrm{a}} \&$ Yun $\mathrm{Du}^{\mathrm{a}}$

${ }^{a}$ Key Laboratory for Environment and Disaster Monitoring and Evaluation, Institute of Geodesy and Geophysics, Chinese Academy of Sciences, Wuhan, China;

${ }^{b}$ The University of Chinese Academy of Sciences, Beijing, China;

${ }^{c}$ School of Geography, University of Nottingham, University Park, Nottingham, UK;

${ }^{d}$ Meteorological Information and Technical Support Center, Hubei Meteorological Administration, Wuhan, China;

${ }^{e}$ School of Public Administration, China University of Geosciences, Wuhan 430074, China. 


\title{
Permanent disappearance and seasonal fluctuation of urban lake area in Wuhan, China monitored with long time series remotely sensed images from 1987 to 2016
}

\begin{abstract}
Lakes are important to the healthy functioning of the urban ecosystem. The urban lakes in Wuhan, China, which is known as "city of hundreds of lakes", are facing substantial threats mainly due to rapid urbanization. This paper focused on detecting the spatial and temporal change of urban lakes in Wuhan, using a long time series of Landsat and HJ-1A remotely sensed data from 1987 to 2016. The permanent disappearance and seasonal fluctuation of 28 main urban lakes were analysed, and their relationships with climatic change and human activities were discussed. The results show that most lakes in Wuhan had shrunk over the past 30 years resulting in a permanent change from water to land. The shrinkage was also most apparent in the central region of the city. Seasonal fluctuations of lake area were evident for most lakes but the relative important driving variable of lake area change varied between subperiods of time for different lakes. The explanatory power of impervious surface to five-year permanent water change is $91.75 \%$, suggesting that urbanization-as increasing impervious surface — had led to the shrinkage of urban lakes in Wuhan. In all, $128.28 \mathrm{~km}^{2}$ five-year permanent water disappeared from 1987 to 2016.
\end{abstract}

Keywords: urban lake; climatic changes; human activities

\section{Introduction}

Lakes are a precious natural resource and play an important role in the healthy functioning of ecosystems. Due to the effects of climatic change and human activities, lakes across the world are under threat, evident notably in relation degradation of quality and areal shrinkage (Du, Ottens, and Sliuzas 2010). Lake shrinkage seriously affects the ecosystems, in 
potentially devastating ways, with impacts propagating to, for example, other ecosystems, local climate and water-holding capacity which would lead to the flood in the rainy season and drought in the dry season. Presently, urbanization is taking place all over the world and has greatly changed the Earth's land surface (Ii 2010; Vitousek et al. 1997). As a result, lakes located within or near cities are more likely to be affected by both climatic changes and human activities. Wuhan, China, is known as "city of hundreds of lakes" (Wang et al. 2017), however, many lakes in the city have shrunk or disappeared in the past decades (Kai et al. 2010; Yang and Ke 2015). These latter changes impact the sustainable development of Wuhan city and concerns such as public health. Therefore, exploring the spatial and temporal dynamics of urban lakes is important to urban ecology and environment, which is becoming a great challenge for future development in the city.

Remote sensing is an important source of data for monitoring surface water resources. With the development of remote sensing technology, various remotely sensed data sets such as those acquired from the Landsat Multispectral Scanning System (MSS) (Brown, Gregory, and Milton 1987), Thematic Mapper (TM) (Hui et al. 2008; Tulbure and Broich 2013; Han, Chen, and Feng 2015; Mueller et al. 2016; Tulbure et al. 2016; Deng et al. 2017), Enhanced Thematic Mapper Plus (ETM+) (Mcfeeters 1996; Li et al. 2013), and Operational Land Imager (OLI) (Byoung Chul, Hyeong Hun, and Jae Yeal 2015; Dao and Liou 2015; Lobo, Costa, and Novo 2015; Wang et al. 2018), as well as data acquired by Advanced Spaceborne Thermal Emission and Reflection Radiometer (ASTER) (Pantaleoni et al. 2009), Moderate 
Resolution Imaging Spectroradiometer (MODIS) (Li et al. 2016), and Sentinel-2 (Du et al. 2016) have made it possible to monitor lakes at different scales.

A variety of methods have been proposed to map surface water dynamics. Common water mapping methods for optical imagery could be categorized into four types (Ji, Zhang, and Wylie 2009): (1) thematic classification method, (2) linear unmixing model, (3) singleband thresholding method, and (4) spectral water index method. The two most commonly used methods are spectral water index method and thematic classification method. In terms of spectral water index method, many indices were proposed such as the Modified Normalized Difference Water Index (MNDWI) (Xu 2006), the Normalized Difference Water Index (NDWI) (Mcfeeters 1996), and the Automated Water Extraction Index (AWEI) (Feyisa et al. 2014). Due to its simplicity and efficiency, spectral water index method is widely used in water extraction. Although some comparative analyses between these water indices have been conducted ( $\mathrm{Li}$ et al. 2013; Rokni et al. 2014; Yang et al. 2015), it is still hard to determine which index performs best in water extraction. In terms of thematic classification method, various classifiers are used to extract surface water including Random Forest (RF) (Liaw and Wiener 2002), Support Vector Machines (SVM) (Gunn 1998), Maximum Likelihood (ML) (Strahler 1980) and Decision Tree (DT) (Friedl and Brodley 1997). Due to its good performance in previous studies (Deng et al. 2017; Tulbure et al. 2016), RF classifier is selected to generate a comprehensive historical record of surface water dynamics with three decades of seasonally continuous time series of Landsat data from 1987 to 2016. 
In general, when remotely sensed images are used to map the changes of lake extent, the water surface area is often used to represent the lake area. A popular method to analyse lake change is by comparing maps of water produced by the classification of remotely sensed images acquired at two time periods (Hui et al. 2008; Feng et al. 2012; Rokni et al. 2014; Yun et al. 2011). This method is intuitive but may not be a reasonable way to describe the real changes in lake area which has obvious seasonal fluctuation. Hence, it is a problem that how to describe the lake change in a more reasonable way. Selecting suitable image pairs, such as those acquired on anniversary dates or days with similar water levels in different years, can help mitigate this problem to some degree. More detailed information in lake temporal change is needed. Meanwhile, the nature and reason for lake change are not made apparent. Specifically, the seasonal fluctuation and permanent disappearance of lakes caused by climatic changes and human activities are hard to differentiate.

To overcome the problem of separating seasonal fluctuation from longer-term trends, that are regarded here as being permanent changes, requires the monitoring of lake change with, for example, long time series of remotely sensed images. Rather than using a small number of images acquired on specific dates, all available remotely sensed images covering the region of interest may be used. Then, the availability of several to tens of image scenes within one year enables the analysis of inter-annual and intra-annual lake change. The fine temporal but coarse spatial resolution images such as MODIS enable the monitoring of lakes over short time intervals, but the coarse spatial resolution of these images cannot meet the requirements for monitoring of urban lakes which are usually very small relative to the pixel 
size. A possible solution to this situation is through the use of Landsat sensor data, which are available since the 1970s with a relatively fine spatial resolution (Ozesmi and Bauer 2002). For example, Rokni et al. (2014) took advantage of the multi-temporal Landsat images to model the spatial-temporal changes of Lake Urmia in the period 2000-2013. Tulbure et al. (2016) made use of the seasonally continuous Landsat data to synoptically map the extent and dynamics of surface water and flooding (1986-2011) over the Murray-Darling Basin. Halabisky et al. (2016)(Halabisky et al. 2016) exploited a time series of Landsat satellite images to reconstruct semi-arid wetland surface water dynamics. Deng et al. (2017) utilized seasonally continuous Landsat TM/ETM+/OLI scenes to evaluate the lake-water extent changes in Wuhan urban agglomeration from 1987 to 2015. However, there still exists a limited understanding of the driving variables of the long-term urban lake area change.

This paper aims to analyse the spatio-temporal change of urban lakes in Wuhan using a long time series remotely sensed images from 1987 to 2016. Although there are some similarities with Deng et al. (2017), the biggest difference is that we not only analyse the spatial-temporal change of urban lake but also analyse the driving variables that causing urban lake change with impervious surface data and climatic data. Based on the generated long time series seasonal urban lake changes, both long-term permanent loss of lake area and the seasonal change of lake area caused by climatic changes and human activity factors are explored. The relative important driving variable in different periods of urban lake change are also analysed, which is useful in understanding the lake area change in Wuhan. 


\section{Materials and Methods}

The research comprised three main steps (Figure 1). The first step involved image

classification and accuracy assessment. The second step focused on calculating water

inundation frequency maps and five-year permanent water maps. It is noted that five-year

permanent water is defined as the permanent water in a five-year period (e.g. the permanent water from 1987 to 1991).The last step addressed the analysis of the spatial-temporal pattern and driving variables of lake changes in Wuhan.

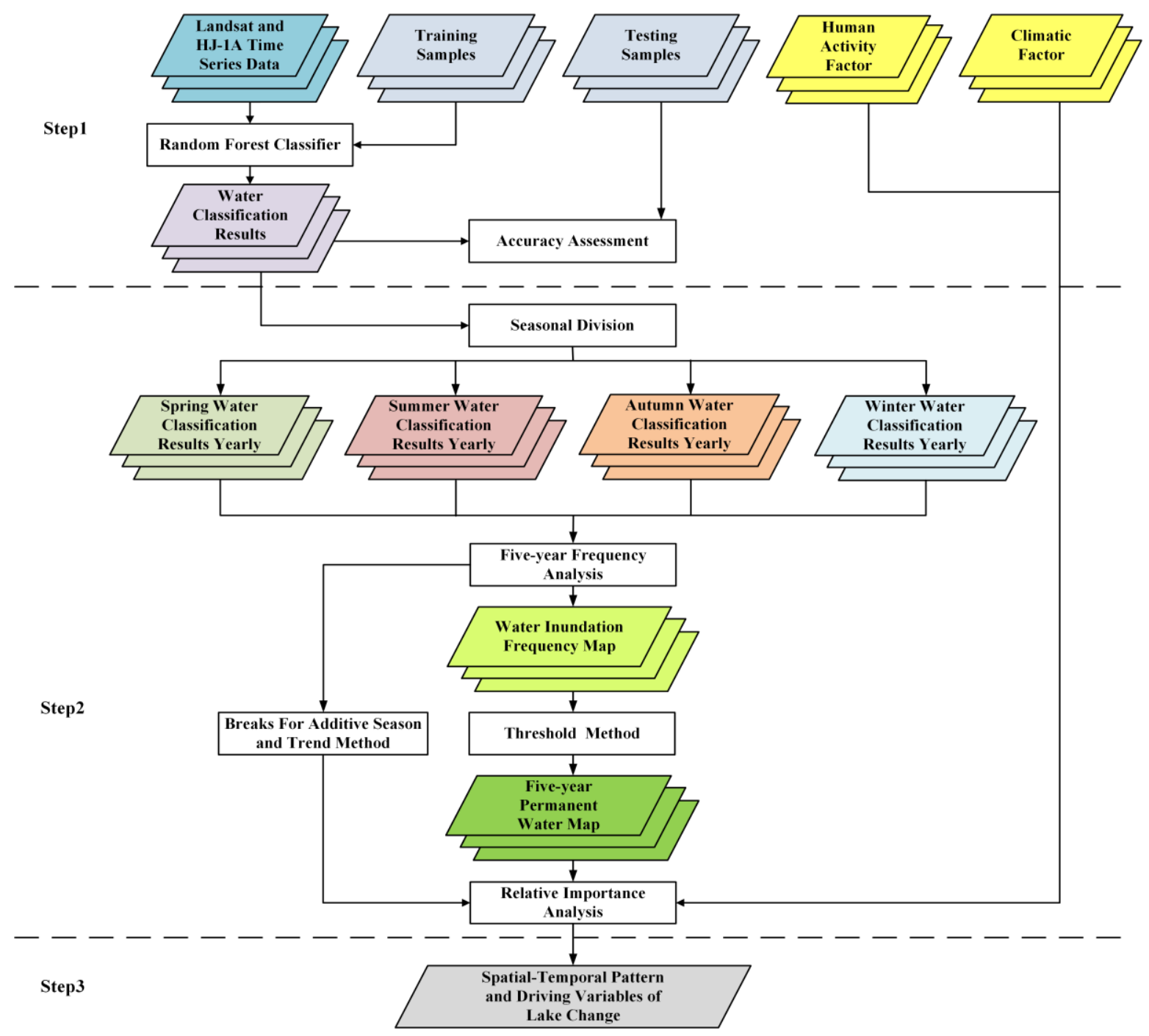

Figure 1. The flowchart of lake change mapping. 


\subsection{Study area}

Wuhan is one of the world's richest cities in terms of surface water resources. It is located between $29^{\circ} 58^{\prime}-31^{\circ} 22^{\prime} \mathrm{N}$ and $113^{\circ} 41^{\prime}-115^{\circ} 05^{\prime} \mathrm{E}$ near the intersection of middle reaches of Yangtze and Han rivers and covers approximately $8494.41 \mathrm{~km}^{2}$. From the "three lines and one road" protection plan published by the Wuhan government in 2015 , the total area of lakes accounts for about $10 \%$ of the Wuhan city area. The topography of Wuhan is monadnock plain impacted by rivers and lakes. The central region is low and flat and the surrounding area is surrounded by hills and fields. Wuhan has a humid subtropical monsoon climate with abundant rainfall and four distinctive seasons.

With the "Reform and Opening Up" policy in the 1980s, the Chinese society and economy grew rapidly in the past decades, leading to rapid urban expansion (Schneider and Mertes 2014). Under the circumstances, urban lakes in Wuhan have also experienced considerable shrinkage over the past three decades. Based on the lake integrity and size, the main 28 lakes of Wuhan were selected (Figure 2). All of these lakes are closed-basin lakes that normally exist throughout the year (i.e. they are not seasonal phenomena). 


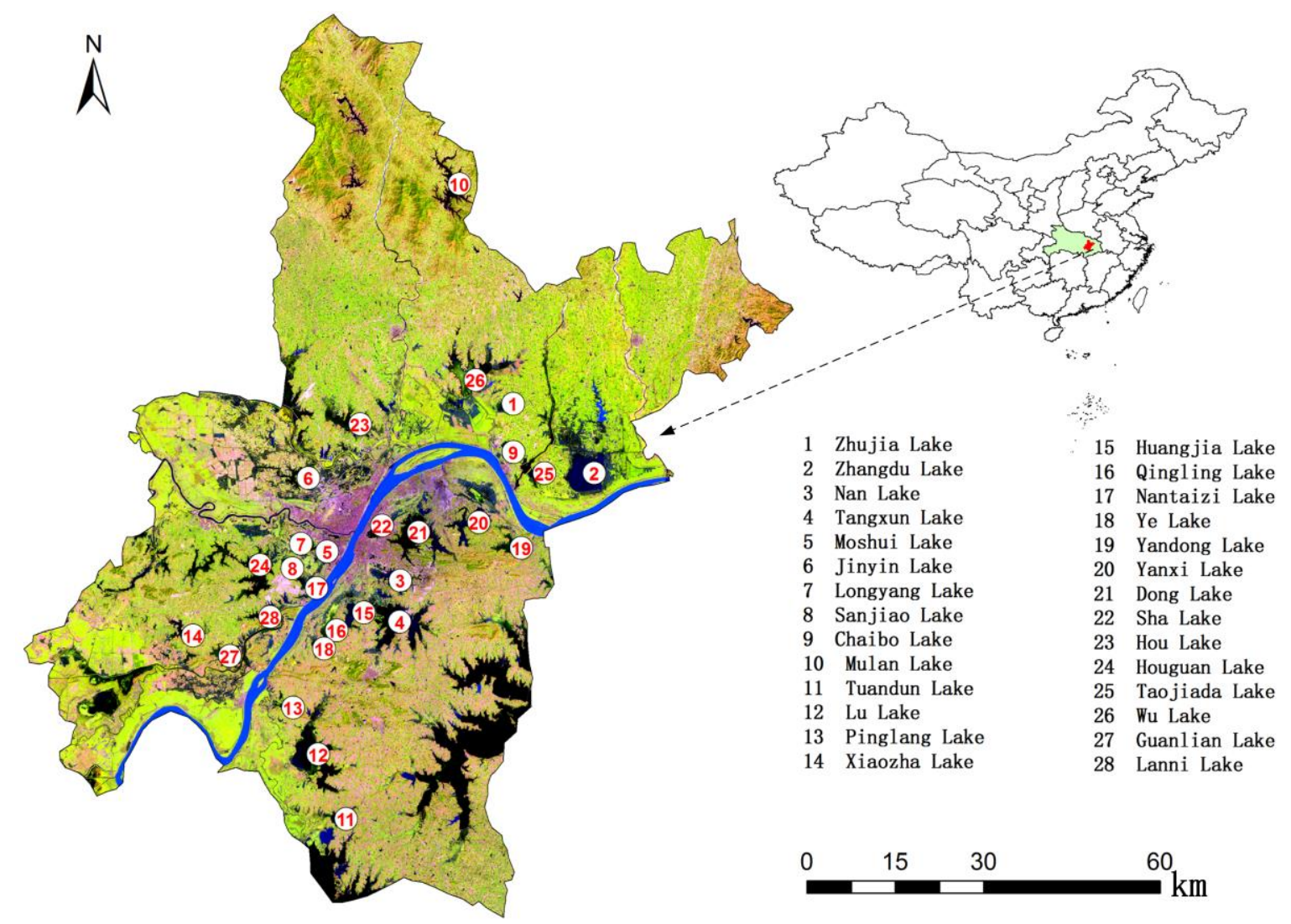

Figure 2. The studied 28 urban lakes in the Wuhan city. The areas shown as black and blue in the Landsat TM image with the combination of bands 5, 4 and 3 on September 29, 1994, are mostly water areas.

\subsection{Datasets}

The main remotely sensed images used in this study were acquired by Landsat sensors including the TM, ETM+ and OLI. All Landsat surface reflectance data available online were downloaded from the US Geological Survey (USGS) Earth Resources Observation and Science (EROS) Center Science Processing Architecture (ESPA) on demand interface (https://espa.cr.usgs.gov/). All Landsat time-series datasets were registered geographically to the WGS84/UTM Zone 49N coordinate system. Notably that the remotely sensed images are selected by visual check to avoid the cloud contamination over lake regions. In the case of 
data shortage, however, the imagery with some cloud contamination still has to be used in this study. Besides Landsat, the HJ-1A satellites launched since 2008, also have a spatial resolution of $30 \mathrm{~m}$, and were used as a supplementary data source. HJ-1A images were downloaded from the China Center for Resource Satellite Data and Application (http://cresda.com/CN/index.shtml). The HJ-1A images were geo-referenced with the Landsat image data, and atmospheric correction processes were performed in ENVI software using the FLAASH module.

Table 1. The used bands of remotely sensed data.

\begin{tabular}{c|c|c|c|c|c|c|c}
\hline \multicolumn{2}{c|}{ Landsat TM } & \multicolumn{2}{c|}{ Landsat ETM+ } & \multicolumn{2}{c}{ Landsat OLI } & \multicolumn{2}{c}{ HJ-1A } \\
\hline $\begin{array}{c}\text { Band } \\
\text { number }\end{array}$ & $\begin{array}{c}\text { Wavelength } \\
(\boldsymbol{\mu m})\end{array}$ & $\begin{array}{c}\text { Band } \\
\text { number }\end{array}$ & $\begin{array}{c}\text { Wavelength } \\
(\boldsymbol{\mu} \mathbf{m})\end{array}$ & $\begin{array}{c}\text { Band } \\
\text { number }\end{array}$ & $\begin{array}{c}\text { Wavelength } \\
(\boldsymbol{\mu m})\end{array}$ & $\begin{array}{c}\text { Band } \\
\text { number }\end{array}$ & $\begin{array}{c}\text { Wavelength } \\
(\boldsymbol{\mu m})\end{array}$ \\
\hline 1 & $0.45-0.52$ & 1 & $0.450-0.515$ & 2 & $0.450-0.515$ & 1 & $0.43-0.52$ \\
\hline 2 & $0.52-0.60$ & 2 & $0.525-0.605$ & 3 & $0.525-0.600$ & 2 & $0.52-0.60$ \\
\hline 3 & $0.63-0.69$ & 3 & $0.630-0.690$ & 4 & $0.630-0.680$ & 3 & $0.63-0.69$ \\
\hline 4 & $0.76-0.90$ & 4 & $0.775-0.900$ & 5 & $0.845-0.885$ & 4 & $0.76-0.90$ \\
\hline 5 & $1.55-1.75$ & 5 & $1.550-1.750$ & 6 & $1.560-1.660$ & & \\
\hline 7 & $2.08-2.35$ & 7 & $2.090-2.350$ & 7 & $2.100-2.300$ & & \\
\hline
\end{tabular}

Table 2. The temporal distribution of Landsat and HJ-1A remotely sensed data. The green, red, orange and blue areas represent spring, summer, autumn, and winter, respectively. The black and red numbers represent the Landsat data and HJ-1A data, respectively. TotalYear represents the total numbers of images in each year, and TotalMonth represents the total numbers of images each month.

\begin{tabular}{c|cccccccccccc|c}
\hline Mear & Jan & Feb & Mar & Apr & May & Jun & Jul & Aug & Sep & Oct & Nov & Dec & TotalYear \\
\hline 1987 & & & & 19 & & & 24 & & 26 & & & 31 & 12 \\
1988 & & & & 30 & & 08 & & 11 & & & 15 & & 12 \\
1989 & & 11 & 07 & & & & & 14 & & & 18 & 04 & 15 \\
1990 & & & & 27 & & & 16 & & 02 & & 21 & 07 & 15 \\
1991 & & & & & 16 & 19 & & & $07 ; 23$ & 08 & & 15 \\
1992 & $11 ; 27$ & 12 & & 16 & & & & & & 25 & $10 ; 26$ & & 21 \\
1993 & 29 & & 02 & & & & & 09 & & 12 & 13 & 31 & 18 \\
1994 & & & 05 & & 08 & 27 & & 29 & 31 & & & 15 \\
1995 & & 04 & & 09 & 27 & 14 & 31 & & 02 & & 05 & 21
\end{tabular}




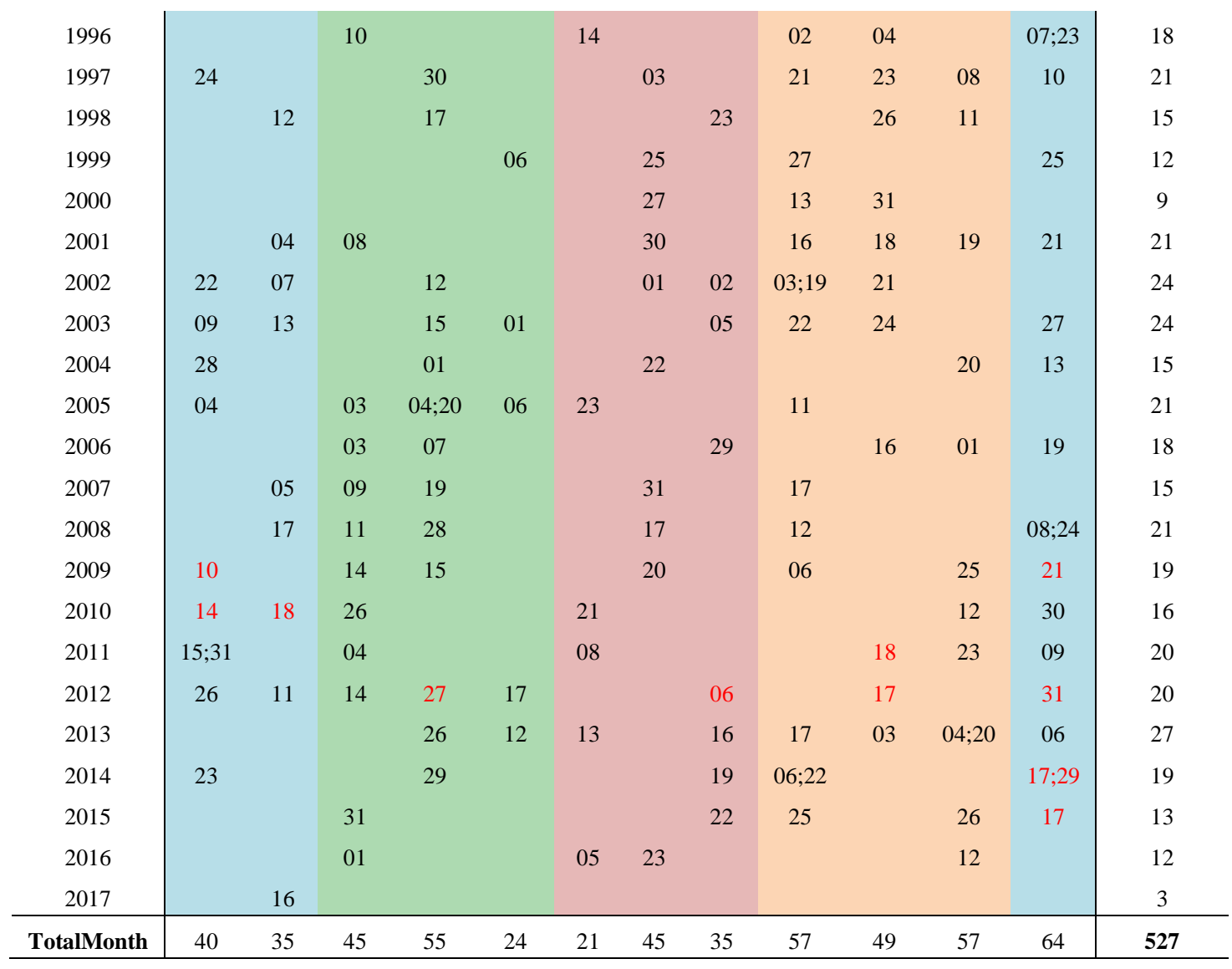

All of the remotely sensed images used have a spatial resolution of $30 \mathrm{~m}$, and the spectral wavebands used are shown in Table 1. The observation times of these images were categorized into four seasons: spring (March to May), summer (June to August), autumn (September to November) and winter (December to the next February, e.g. the winter in 1991 started from the December in 1991 to the February in 1992). The temporal distribution and seasonal division of remotely sensed data are shown in Table 2. Three Landsat images or two HJ-1A images are needed to cover the whole study area. In all, 527 images including $24 \mathrm{HJ}-$ 1A images and 513 Landsat images were used in this study. Remotely sensed images were available for each of the four seasons in almost all years during the study period, except summer in 1992, spring in 2000 and winter in 1998 and 2005. 
In order to analyse the factors driving changes in the urban lake area, data on climatic changes and on human activities were also acquired. In terms of the climate data, monthly precipitation, evaporation, and temperature during 1987 - 2016 were obtained from the China Meteorological Data Network (http://data.cma.cn). In terms of human activities, a 30m, annual impervious surface dataset for Wuhan produced from 1987 to 2016 by using all available Landsat images (Shi et al. 2017) was used.

\subsection{Urban lake mapping}

\subsubsection{Random forest classification}

The random forest algorithm (Belgiu and Drăguţ 2016) was applied to map waterbodies for each remotely sensed image. The random forest is an ensemble classifier that constructs many classification trees by a random subset of training data and predictors. The classification trees in $\mathrm{RF}$ are grown to maximum size without pruning and the outputted classes were aggregated via majority voting across all individual trees in the forest. Additionally, RF classifier has a built-in "Out-of-Bag" (OOB) accuracy assessment. OOB accuracy, which is unbiased and can be used to substitute the cross-validation or independent test datasets, was used to assess the performance of classification.

Given that there are four different kinds of remotely sensed images (Landsat TM, ETM+, OLI as well as HJ-1A), different RF classifiers were developed for each sensor. For each RF classifier, different explanatory variables were used. For use with Landsat images, the variables used were the surface reflectance acquired in the selected spectral wavebands 
(Chander, Markham, and Helder 2009) and four spectral indices: the Normalized Difference Water Index (NDWI), the Modified Normalized Difference Water Index (MNDWI), the Normalized Difference Vegetation Index (NDVI), and the Normalized Difference Built-up Index (NDBI) . With the HJ-1A images, as only data in four spectral bands were available, surface reflectance in every spectral band, NDVI and NDWI were used.

For each RF classifier, the training samples were selected from high spatial resolution images provided by Google Earth. Moreover, because Landsat or HJ images were not temporally coincident with these high-resolution images, visual interpretation of the time series of Landsat or HJ images were also used to obtain the training data. Table 3 lists the number of training samples for the four RF classifiers. A total of 343,412 training samples including 160,563 water training samples and 182,849 non-water training samples were selected from the corresponding remotely sensed images.

Table 3. The number of training samples

\begin{tabular}{c|cc}
\hline Class & Water & Non-water \\
RF classifier & & 101327 \\
\hline Landsat 5 TM & 96550 & 35606 \\
Landsat 7 ETM+ & 25740 & 34836 \\
Landsat 8 OLI & 28898 & 11080 \\
HJ-1A & 9375 & \\
\hline
\end{tabular}

Four RF classifiers' OOB scores were computed depending on different numbers of classification trees. The high OOB score indicates the good performance of random forest classifier. Different numbers (i.e. 10, 20,30,40,50,60,70,80,100,150,200) of classification trees were tested and their performances in OOB score are shown in Figure 3. Given that random forest classifier's accuracy and efficiency are equally important, the numbers of classification trees are all set to 80 for those four kinds of remotely sensed data. 


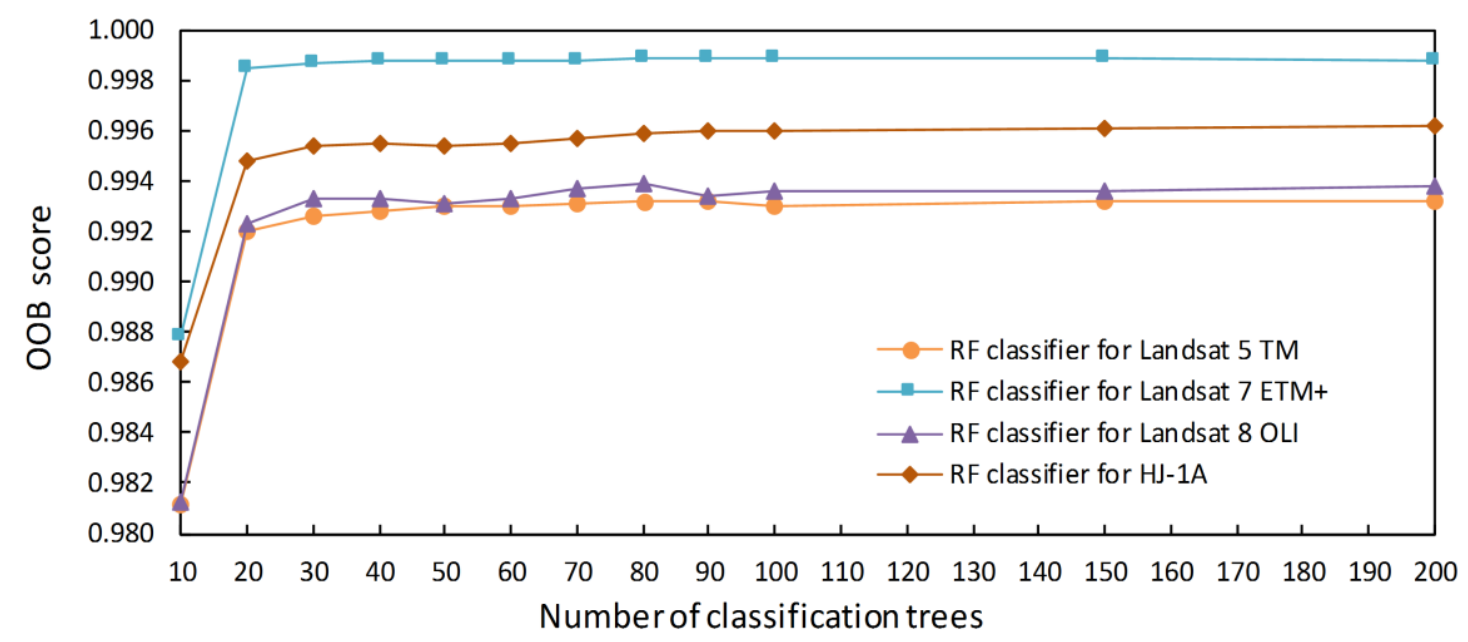

Figure 3. The OOB score for each classifier.

It was evident that the water maps contained misclassified pixels which caused mainly by imagery quality problems (i.e. missing scan line imagery and cloud contaminated imagery) and the presence of aquatic plants in lakes. To increase the accuracy of the water maps, post-processing steps were applied. The data gap caused by cloud, haze, cloud shadow and SLC-off was filled by a temporal filter method (Tulbure and Broich 2013). For example, the cloud-obscured pixel of an image acquired in the winter of 1992 was assigned as water, if most pixels in the same location and season during 1991 - 1993 were labelled as water. In addition, misclassified water areas covered by aquatic plants were manually corrected. For each season in a year, there may be several class label images from RF classifiers. In order to generate the most representative classification result for this season, several class label images were merged into one based on the majority rule. With the majority rule, the class label which held a majority was recognized as the representative class label for the pixel. With the post-processing analysis, seasonal water classification maps from 1987 to 2016 were produced. 


\subsubsection{Accuracy assessment}

In general, a binary classification system (e.g. water and non-water classes) produces relative high classification accuracy (Moknatian, Piasecki, and Gonzalez 2017). From previous studies, the water and non-water classification accuracy produced by RF classifier is very high. Given that most errors in image classification are spatially concentrated at the boundaries between land cover classes rather than in the homogeneous class interior (Smith et al. 2003; Foody 2002), an edge sampling method was employed to assess the accuracy of water classification in this study (Tulbure and Broich 2013). While assessing the classification accuracy with high-resolution data such as that available in Google Earth would have been ideal, high-resolution images are always not temporally coincident with Landsat data acquisition. Testing samples were then collected based on the Landsat images.

It was impractical to assess the accuracy of all classifications, especially as suitable reference data were not always available. Here, accuracy assessment focused on the labelling for 20 periods, specifically the class labels observed the four seasons of the years 1990, 1996, 2001, 2006 and 2013. The dates of the 20 class labels results are shown in Table 5. In this study, 250 water testing samples and 250 non-water testing samples were collected by visually interpreting the Landsat image for each time series. In all, 10,000 testing samples were collected. Classification accuracy was computed as Overall Accuracy (OA) of water and non-water using a confusion matrix (Foody 2002). As the aim was to indicate the accuracy of the classification rather than of the maps in general, the core focus was on the 
overall accuracy of the allocations in the sample; map accuracy assessment would require adjustment for the sample design used.

\subsection{Temporal change analysis of lake area}

Using the long time series of lakes area developed, the temporal change trend line and, if appropriate, the abrupt time point of change were analysed for lakes individually with the Breaks For Additive Season and Trend (BFAST) method (Verbesselt et al. 2010). BFAST is an iterative algorithm that decomposes time series into trend, seasonal, and remainder components. The general model is described with the following equation:

$$
Y_{t}=T_{t}+S_{t}+e_{t}(t=1, \ldots, \ldots, n)
$$

where $Y_{t}$ is the observed data at time $t, T_{t}$ is the trend component, $S_{t}$ is the seasonal component, $e_{t}$ is the remainder component characterizing the residual noise in the input time series $Y_{t}$, and $\mathrm{n}$ is the number of observed values. It is assumed that the trend component $T_{t}$ is piecewise linear and the seasonal component $S_{t}$ can be fitted as a dummy model with segments.

The whole study period was divided into several sub-periods by the abrupt time point analysis. The relative importance analysis was then employed to find out which variable has the most important contribution to lake change during a certain sub-period.

\subsection{Spatial change analysis of lake area}

In order to analyse the spatial pattern of lake changes, a frequency analysis approach (Pekel 
et al. 2016) was applied to all seasonal water classification maps to produce water inundation frequency maps. Water inundation frequency is the quotient of the water detection times divided by all observation times during a period. In this study, water inundation frequency maps were calculated for each 5-year period. Hence, the 30-year study period (i.e. 1987 2016) was divided into six 5-year periods: period1 (1987 - 1991), period2 (1992 - 1996), period3 (1997 - 2001), period4 (2002 - 2006), period5 (2007 - 2011) and period6 (2012 2016). The resultant water inundation frequency maps were divided into six grades: 0 - 5, 5 $-25,25-50,50-75,75-95$ and $95-100$. Among them, 0 - 5 indicated that frequency value was equal or greater than $0 \%$ and equal or less than 5\%; 5 - 25 indicated that frequency value was greater than $5 \%$ and equal or less than $25 \% ; 25$ - 50 indicated that frequency value was greater than $25 \%$ and equal or less than $50 \%$; 50 - 75 indicated that frequency value was greater than $50 \%$ and equal or less than $75 \% ; 75$ - 95 indicated that frequency value was greater than $75 \%$ and less than $95 \%$; 95 - 100 indicated that frequency value was equal or greater than $95 \%$ and equal or less than $100 \%$. By considering the uncertainty of remotely sensed image classification (i.e. some degree of misclassification is inevitable) in this study, pixels with the grade 0 - 5 are recognized as non-water area and pixels with the grade 95 100 are recognized as five-year permanent water area. The other grades 5 - 25, $25-50,50-$ 75, 75 - 95 are recognized as low water inundation frequency area, low-medium water inundation frequency area, high-medium water inundation frequency area and high water inundation frequency area, respectively. 


\section{Results}

\subsection{Accuracy assessment}

Based on the edge sampling method, the OA of 20 images are shown in Table 4 . In terms of seasonal average OA, the summer $(99.2 \%)$ is the highest and the winter $(94.5 \%)$ is the lowest. In all, the OA is high enough to study the surface water changes.

Table 4. Overall accuracy for each season in the year 1990, 1996, 2001, 2006 and 2013

\begin{tabular}{|c|c|c|c|c|c|c|}
\hline Season & 1990 & 1996 & 2001 & 2006 & 2013 & Average \\
\hline Spring & 99.5\% (Apr.27) & $99.5 \%$ (Mar.10) & $97.5 \%$ (Mar.08) & $100.0 \%$ (Apr.07) & $90.0 \%$ (Apr.26) & $97.3 \%$ \\
\hline Summer & $97.5 \%$ (Jul.16) & 99.5\% (Jun.14) & $100.0 \%(J u l .30)$ & 99.0\% (Aug.29) & $100.0 \%$ (Aug. 16) & $99.2 \%$ \\
\hline Autumn & $100.0 \%$ (Sept.02) & $99.0 \%$ (Oct.04) & $99.0 \%$ (Oct.18) & $86.0 \%$ (Oct.16) & $98.0 \%$ (Oct.03) & $96.4 \%$ \\
\hline Winter & $92.5 \%$ (Dec.07) & $98.5 \%($ Dec. 23$)$ & $91.5 \%$ (Dec. 21$)$ & $93.5 \%$ (Dec.19) & $96.5 \%$ (Dec.06) & $94.5 \%$ \\
\hline Average & $97.4 \%$ & $99.1 \%$ & $97.0 \%$ & $94.6 \%$ & $96.1 \%$ & $96.8 \%$ \\
\hline
\end{tabular}

\subsection{Temporal changes of lake surface area and their driving variables}

Figure 4 shows the seasonal and long-term lake surface area changes for 28 lakes in Wuhan city. The trend line and abrupt time point for each lake are also shown. The trend lines of seasonal change in lake areas were various. For example, lakes such as Sha Lake, Nan Lake, and Nantaizi Lake, had large fluctuations at the start of the study period, a large drop in the middle of the study period and a small fluctuation by the end of the study period. Chaibo Lake, Taojiaoda Lake, and Wu Lake have relative steady trend lines. Dong Lake, Yanxi Lake, and Zhujia Lake had decreasing trend lines. 

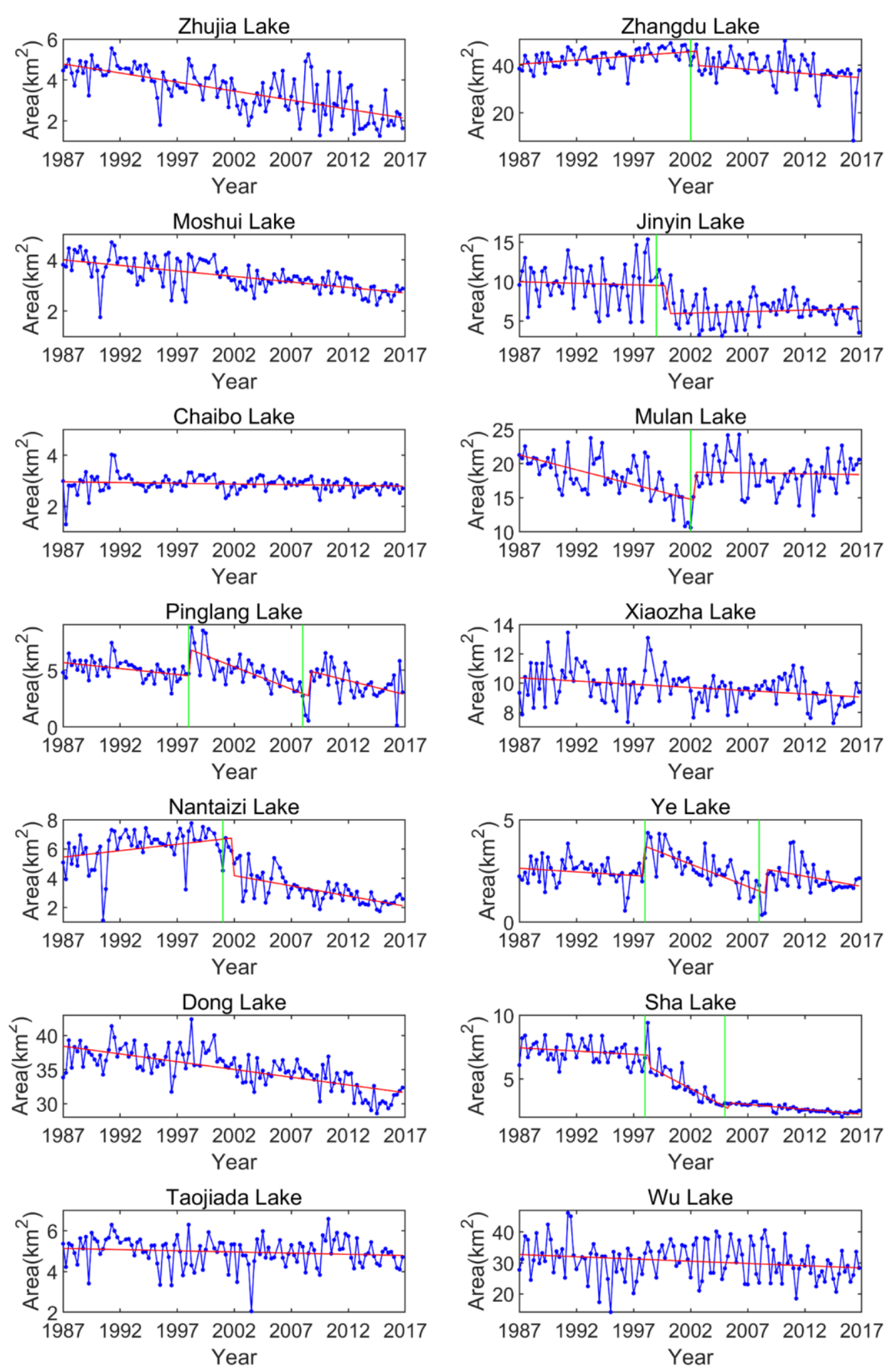

(i) 

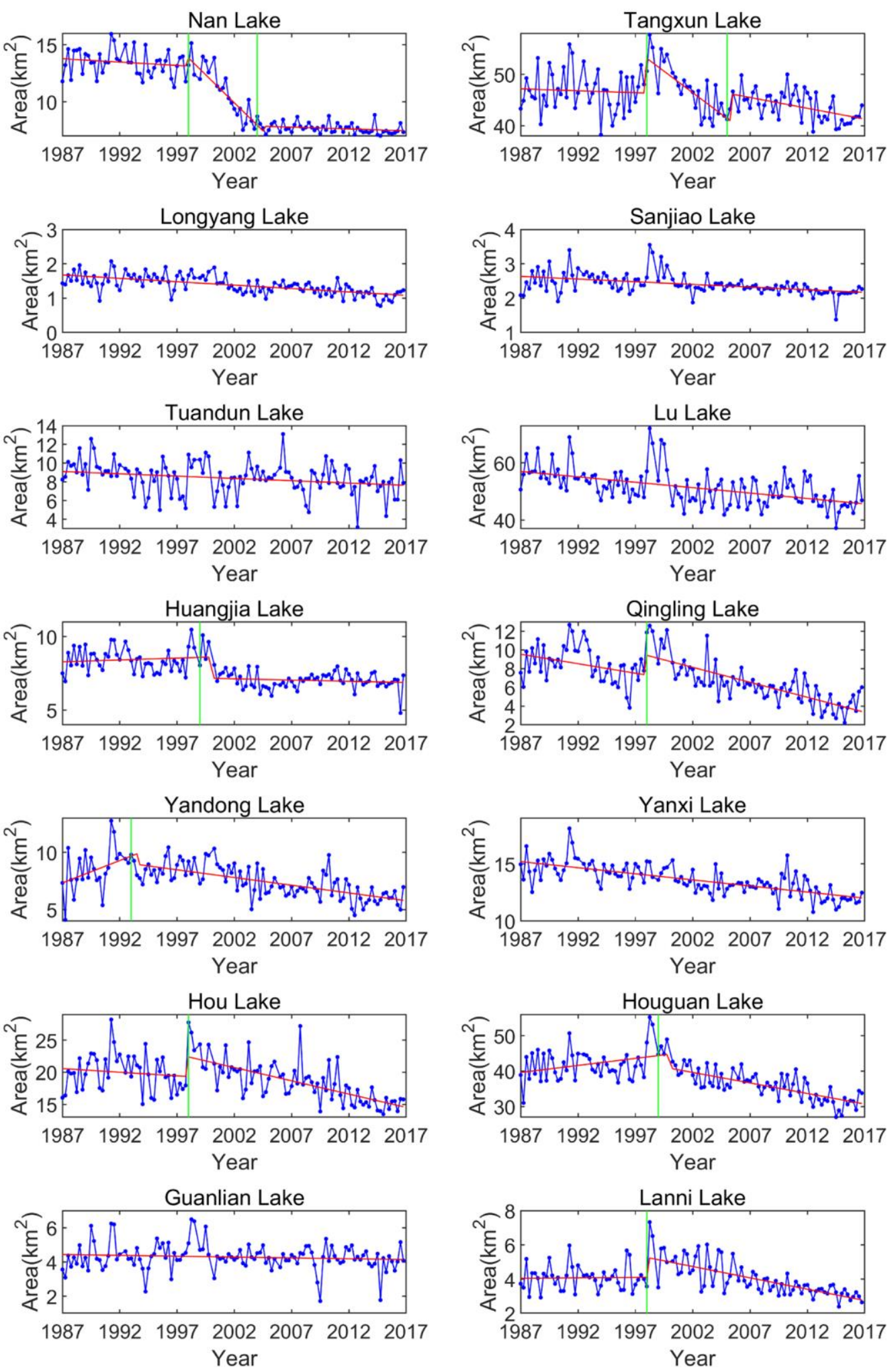

Trend Line — Abrupt Time Point

(ii)

Figure 4. Seasonal and long-term lake surface area changes for 28 lakes in Wuhan city 


\subsection{Spatial changes in water inundation frequency}

Figure 5 shows the six 5-year water inundation frequency maps from 1987 to 2016 . In general, the whole water area substantially declined from the period of 1987 - 1991 to the period of 2013 - 2016. The relatively low water inundation frequency distribution was concentrated and was located in the west-central area and the south-west corner of the study area, because the former area has a rapid urban expansion and the latter area is mostly covered by the paddy field. It was evident that the central parts of the lakes tended to be stable and stay as water with the relatively high frequency and the surrounding lake edge area tend to switch between water and land with the relatively low frequency. Hence, the frequency gradually decreased from the centre to the edge of the lakes.

Figure 6 shows the whole lake area changes quantitatively in Wuhan by considering three representative frequency grades. Among them, 5 - 50 represented the low water inundation frequency; 50 - 95 represented the high water inundation frequency, while 95 100 represented the five-year permanent water. It was found that the water area with the frequency $5-50$ and 50 - 95 increased first and then decreased. Both of the maximums of water area with the frequency 5 - 50 and 50 - 95 appeared in the period of 1997 - 2001 when a great flood happened. The water area within the frequency range of $95-100$ had a significant downward trend as a whole, but had a rebounded somewhat in the period of 1997 - 2001. The downward trend had a correlation with urbanization, while the small rebound might be triggered by the great flood in 1998. In all, the five-year permanent water area 
decreased by $20.12 \%$ and the disappeared five-year permanent water area is $128.2797 \mathrm{~km}^{2}$ from 1987 to 2016.
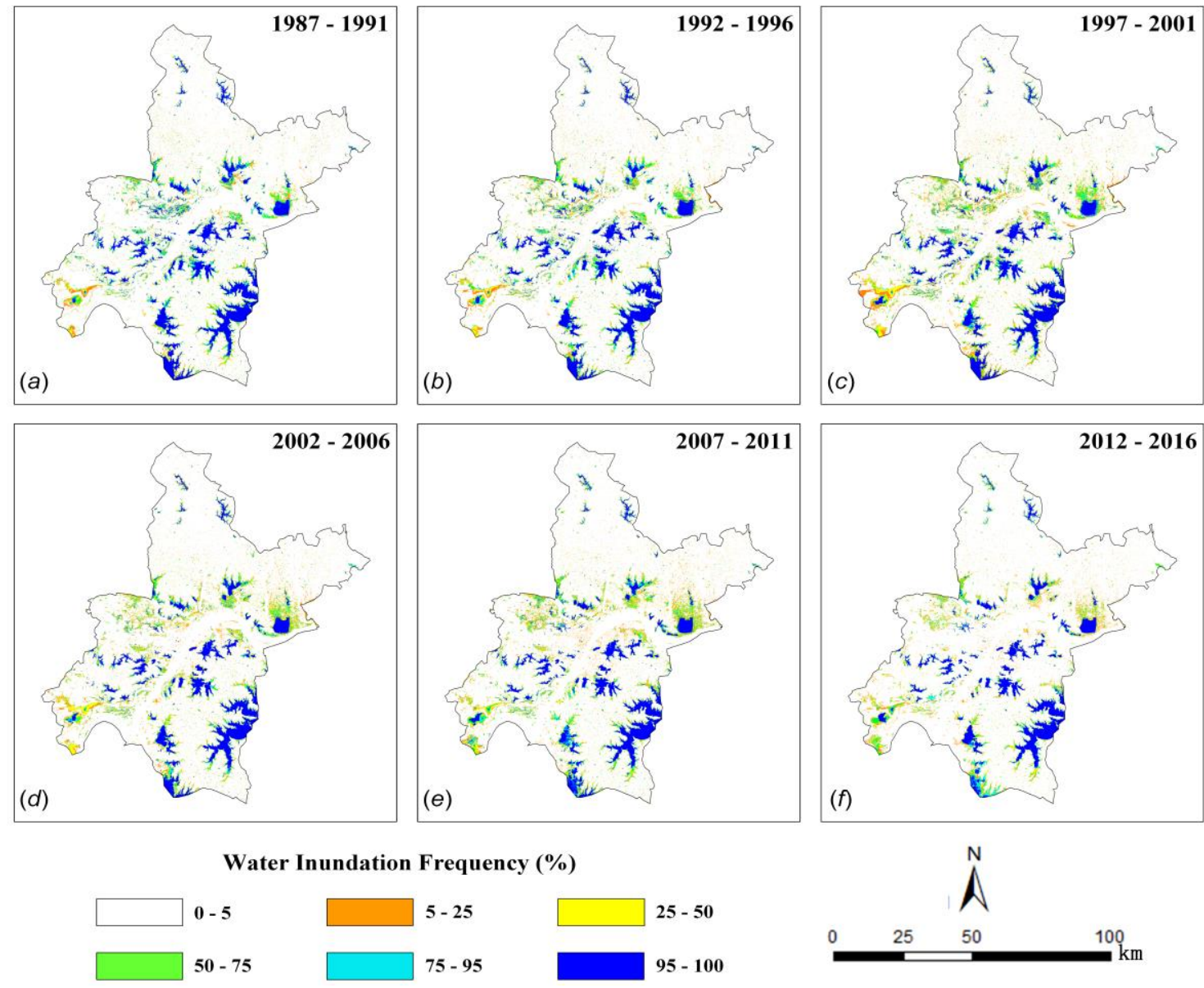

Water Inundation Frequency (\%)

Figure 5. Five-year water inundation frequency maps of Wuhan from 1987 to 2016

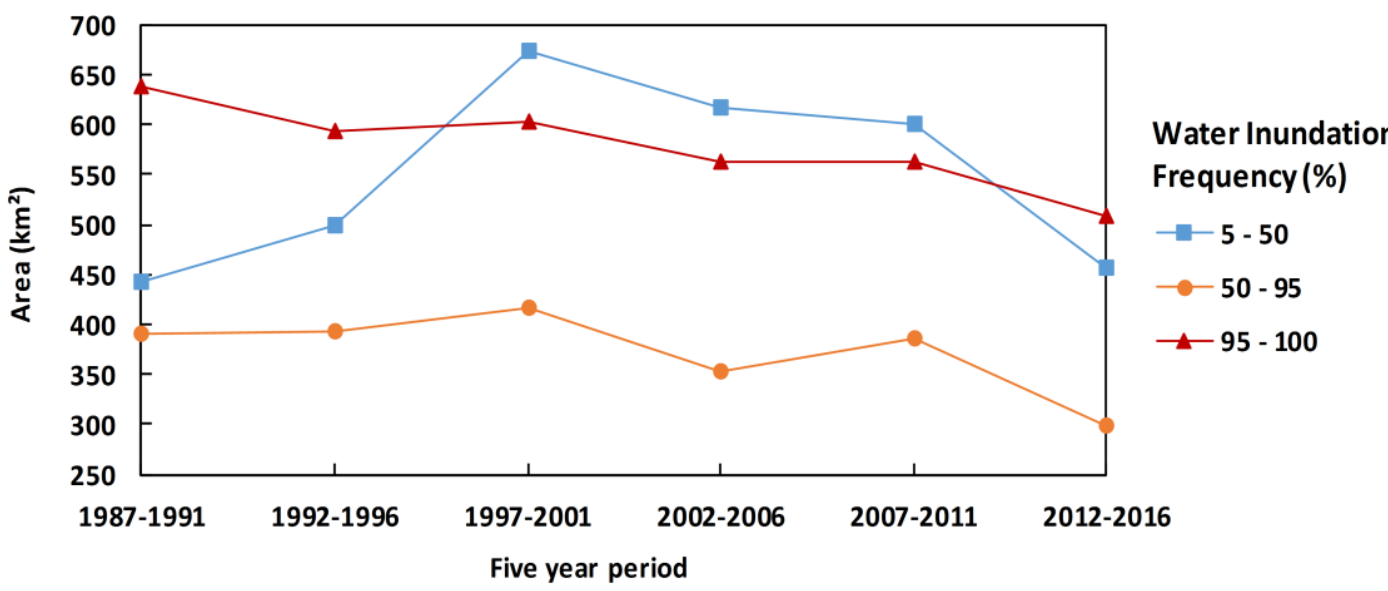

Figure 6. Water area change with the representative water inundation frequency 


\subsection{Changes in five-year permanent waterbodies and their driving variables}

Based on the above analysis, for each lake, the area with a low water inundation frequency appears to arise because of climatic changes, reflected in changes in precipitation, while the area with a high water inundation frequency is mainly caused by human activities, such as urbanization. More importantly, the change of five-year permanent water area is one of the most valuable variables to characterize the change of urban lakes in a long period.

Figure 7 shows the changes in five-year permanent waterbodies in Wuhan during the six periods. Taken as a whole, some five-year permanent water disappeared in the early periods (i.e. the red, orange or yellow area in Figure 7) is located in the centre of Wuhan. That in part reflected the spatial pattern of urban expansion from the centre to edge in the Wuhan city.

Three sub-graphs were shown to enlarge the five-year permanent water change of the representative lakes, including Sha Lake, Nan Lake, and Dong Lake (Figure 7). In general, the five-year permanent water change of lakes extent was least at the lake centre and increased near the lake shore. In terms of Sha Lake and Nan Lake, five-year permanent water disappeared in the early periods is located in the north-east and north-west, respectively. From the sub-graph of Sha Lake, a tiny thread in the middle of Sha Lake disappeared during the period 2007 - 2011. Using Google Earth data as a reference, the tiny thread is proved to be Sha Lake Bridge which built in 2009 and completed in 2011. Similarly, as shown in subgraph of Dong Lake, the thread is proved to be Dong Lake Tunnel which disappeared during the period 2012-2016, and Dong Lake Tunnel was built in 2012 and completed in 2015. 


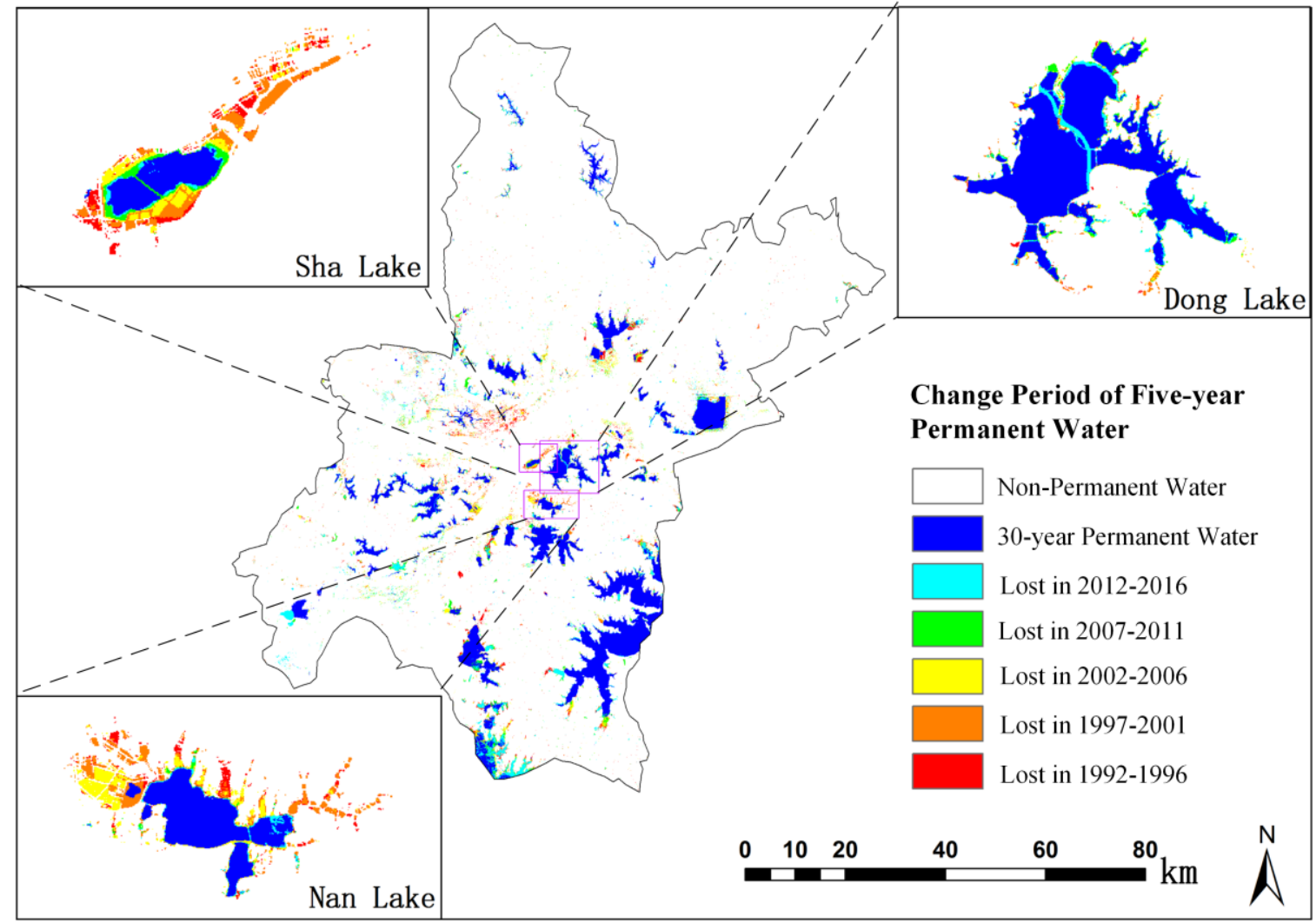

Figure 7. Changes of five-year permanent waterbodies in Wuhan 
Table 5. The change areas and rates of five-year permanent waterbodies for all 28 lakes and the red numbers represent the maximum change rate

\begin{tabular}{|c|c|c|c|c|c|c|c|c|c|c|c|c|c|}
\hline \multirow{2}{*}{ Lake ID } & \multirow{2}{*}{ Lake Name } & \multicolumn{6}{|c|}{ Area $\left(\mathbf{k m}^{2}\right)$} & \multicolumn{6}{|c|}{ Change Rate (\%) } \\
\hline & & $\begin{array}{c}\text { Period1 } \\
\text { 1987-1991 }\end{array}$ & $\begin{array}{l}\text { Period2 } \\
\text { 1992-1996 }\end{array}$ & $\begin{array}{c}\text { Period3 } \\
\text { 1997-2001 }\end{array}$ & $\begin{array}{c}\text { Period4 } \\
\text { 2002-2006 }\end{array}$ & $\begin{array}{c}\text { Period5 } \\
\text { 2007-2011 }\end{array}$ & $\begin{array}{c}\text { Period6 } \\
\text { 2012-2016 }\end{array}$ & Period(1-2) & Period(2-3) & Period(3-4) & Period(4-5) & Period(5-6) & Period(1-6) \\
\hline 1 & Zhujia Lake & 3.95 & 2.79 & 2.40 & 1.56 & 1.31 & 1.13 & -29.35 & -14.15 & -34.91 & -16.38 & -13.79 & -71.54 \\
\hline 11 & Tuandun Lake & 8.04 & 7.01 & 6.95 & 6.61 & 5.40 & 2.44 & -12.80 & -0.83 & -4.92 & -18.27 & -54.84 & -69.65 \\
\hline 16 & Qingling Lake & 7.46 & 6.00 & 5.67 & 4.25 & 3.43 & 2.29 & -19.58 & -5.47 & -25.04 & -19.30 & -33.25 & -69.30 \\
\hline 17 & Nantaizi Lake & 5.35 & 5.30 & 4.26 & 2.16 & 1.98 & 1.77 & -0.87 & -19.59 & -49.36 & -8.42 & -10.70 & -66.99 \\
\hline 22 & Sha Lake & 6.14 & 5.42 & 3.74 & 2.88 & 2.38 & 2.16 & -11.81 & -30.90 & -23.10 & -17.38 & -9.00 & -64.77 \\
\hline 13 & Pinglang Lake & 4.48 & 4.25 & 4.13 & 3.10 & 1.88 & 1.80 & -5.11 & -2.75 & -24.89 & -39.54 & -4.08 & -59.80 \\
\hline 7 & Longyang Lake & 1.45 & 1.32 & 1.25 & 1.04 & 0.97 & 0.71 & -9.16 & -5.38 & -16.56 & -7.42 & -26.93 & -51.49 \\
\hline 6 & Dongxi Lake & 7.39 & 6.47 & 5.66 & 4.98 & 4.81 & 3.97 & -12.48 & -12.48 & -12.12 & -3.45 & -17.46 & -46.35 \\
\hline 3 & Nan Lake & 12.07 & 11.28 & 9.18 & 7.30 & 7.15 & 6.68 & -6.59 & -18.54 & -20.56 & -2.02 & -6.61 & -44.69 \\
\hline 19 & Yandong Lake & 6.99 & 6.65 & 5.91 & 5.35 & 4.84 & 4.05 & -4.84 & -11.20 & -9.39 & -9.55 & -16.42 & -42.12 \\
\hline 27 & Guanlian Lake & 3.76 & 3.73 & 3.71 & 3.47 & 3.02 & 2.29 & -0.60 & -0.55 & -6.45 & -13.09 & -24.09 & -38.99 \\
\hline 28 & Lanni Lake & 3.46 & 3.44 & 3.41 & 3.02 & 2.74 & 2.22 & -0.65 & -0.84 & -11.27 & -9.58 & -18.89 & -35.89 \\
\hline 5 & Moshui Lake & 3.48 & 3.21 & 3.00 & 2.66 & 2.50 & 2.24 & -7.86 & -6.65 & -11.09 & -6.15 & -10.41 & -35.69 \\
\hline 18 & Ye Lake & 2.13 & 2.03 & 1.93 & 1.63 & 1.45 & 1.40 & -4.40 & -5.00 & -15.92 & -10.80 & -3.54 & -34.29 \\
\hline 24 & Houguan Lake & 36.09 & 35.15 & 33.91 & 31.46 & 29.60 & 25.24 & -2.60 & -3.54 & -7.20 & -5.92 & -14.74 & -30.06 \\
\hline 23 & Hou Lake & 16.19 & 15.56 & 15.19 & 14.11 & 13.16 & 11.97 & -3.88 & -2.40 & -7.11 & -6.72 & -9.06 & -26.08 \\
\hline 12 & Lu Lake & 44.94 & 41.90 & 40.40 & 39.39 & 37.21 & 33.74 & -6.76 & -3.58 & -2.50 & -5.54 & -9.33 & -24.93 \\
\hline 26 & Wu Lake & 25.60 & 23.58 & 23.34 & 22.46 & 21.01 & 19.54 & -7.88 & -1.03 & -3.78 & -6.46 & -6.97 & -23.66 \\
\hline 20 & Yanxi Lake & 13.10 & 12.82 & 12.25 & 11.50 & 10.97 & 10.02 & -2.15 & -4.42 & -6.10 & -4.60 & -8.70 & -23.51 \\
\hline 21 & Dong Lake & 34.57 & 33.68 & 32.68 & 31.28 & 30.09 & 27.17 & -2.59 & -2.97 & -4.29 & -3.80 & -9.72 & -21.43 \\
\hline 15 & Huangjia Lake & 7.34 & 7.11 & 6.93 & 6.60 & 6.55 & 5.78 & -3.14 & -2.61 & -4.70 & -0.78 & -11.72 & -21.25 \\
\hline 10 & Mulan Lake & 15.84 & 15.37 & 14.98 & 14.92 & 14.28 & 12.52 & -2.95 & -2.56 & -0.39 & -4.26 & -12.31 & -20.93 \\
\hline 8 & Sanjiao Lake & 2.26 & 2.21 & 2.19 & 2.06 & 1.99 & 1.80 & -2.19 & -1.06 & -6.01 & -3.41 & -9.24 & -20.26 \\
\hline 14 & Xiaozha Lake & 8.52 & 8.42 & 8.33 & 7.98 & 7.78 & 6.86 & -1.29 & -1.04 & -4.19 & -2.53 & -11.82 & -19.55 \\
\hline 25 & Taojiada Lake & 4.52 & 4.36 & 4.24 & 4.00 & 3.92 & 3.65 & -3.62 & -2.56 & -5.75 & -2.12 & -6.80 & -19.26 \\
\hline 2 & Zhangdu Lake & 40.89 & 40.78 & 39.01 & 37.71 & 36.17 & 34.25 & -0.27 & -4.34 & -3.35 & -4.06 & -5.31 & -16.22 \\
\hline 4 & Tangxun Lake & 43.01 & 42.27 & 41.26 & 39.83 & 38.77 & 36.42 & -1.72 & -2.40 & -3.46 & -2.67 & -6.05 & -15.31 \\
\hline 9 & Chaibo Lake & 2.59 & 2.58 & 2.52 & 2.47 & 2.37 & 2.29 & -0.52 & -2.27 & -2.25 & -3.76 & $-3.64 \%$ & -11.86 \\
\hline
\end{tabular}


Table 5 shows the change areas and rates of five-year permanent waterbodies for all 28 lakes. The order of entries in this table is ranked in terms of the rate of change between Period1 and Period6. Basically, the five-year permanent water areas all decreased in this period. The largest change rate reaches $71.54 \%$, while the lowest change rate is $11.86 \%$. Seven lakes have the decreased rate larger than $50 \%$, and the lakes with the top five decreased rates are Zhujia Lake, Tuandun Lake, Qingling Lake, Nantaizi Lake, and Sha Lake. All the top five lakes' five-year permanent water change rate is higher than $60 \%$ from Period1 to Period6, indicating that a large number of five-year permanent waterbodies had disappeared in these lakes. The red number shown in Table 5 represents the maximum change rate in the five periods for each lake. In all, only one maximum change rate appeared at Period (1 - 2) and Period (2 - 3) respectively; Five maximum change rate appeared at Period (3 - 4); Two maximum change rate appeared at Period (4 - 5) and the remaining 19 maximum change rate appeared at Period (5 - 6).

\section{Discussion}

Substantial variations in urban lake extent were observed. The change of climatic factors (i.e. precipitation, temperature, evaporation and the difference between precipitation and evaporation) and human activity (i.e. impervious surface) from 1987 to 2016, as shown in Figure 8, were used to analyse the factors that may be driving the changes in the urban lakes of Wuhan city. The seasonal temperature data were calculated by averaging all monthly data in each season. The seasonal precipitation data and evaporation data were calculated by summing all monthly data in each season. The seasonal difference between precipitation and evaporation data was calculated by seasonal precipitation minus seasonal evaporation. It is noticed that the trend lines of seasonal change of climatic factors remain steady from 1987 to 2016 and the trend line of the annual impervious surface area kept increasing substantially. Given temperature always has a very small 
impact on the hydrologic cycle for closed-basin lakes, we only use the difference between precipitation and evaporation as climatic factors, and impervious surface as the human activities factor in the following analysis.
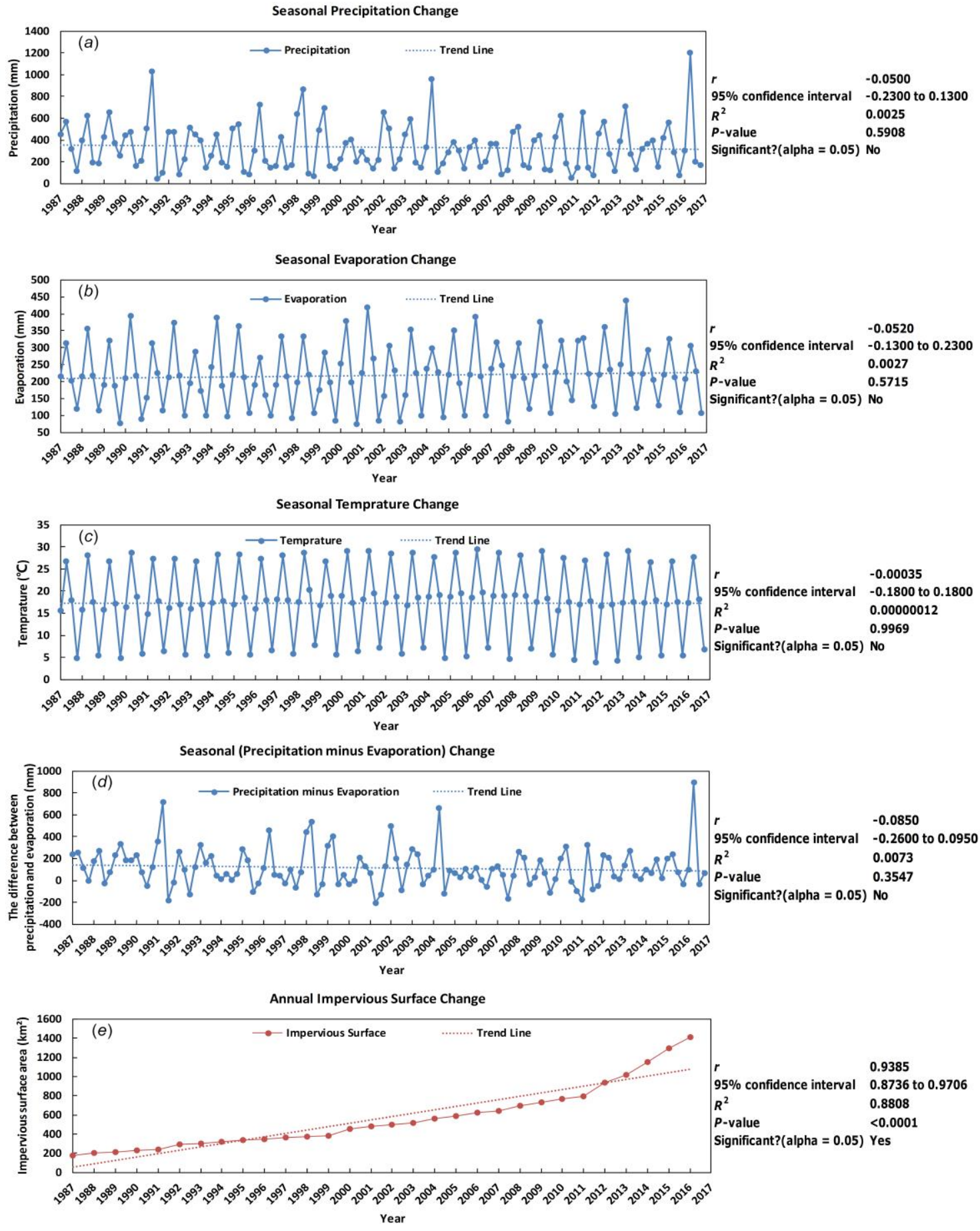

Figure 8. The change of climate and human activity from 1987 to 2016. "Precipitation minus Evaporation" represents the difference between precipitation and evaporation. 
Three lakes with the representative trend line were selected to analyse the driving variables in lake area change. Chaibo Lake has a slow downward trend, Dong Lake has a rapid downward trend, and Nan Lake has both trends together. Figure 9 shows the relative importance between the seasonal lake area and the seasonal difference of precipitation and evaporation, and the relative importance between the annual lake area, derived by averaging the seasonal lake areas for the year, and the annual impervious surface calculated with a $5 \mathrm{~km}$ buffer zone of the lake boundary. The linear regression was used to describe the relationship between the lake area and its driving variables. The coefficient of determination $\left(R^{2}\right)$ is often higher for "Impervious Surface" than "Precipitation minus Evaporation" except that in the period 1987 - 1998 for Nan Lake. This means “Impervious Surface" has a stronger explanatory power than "Precipitation minus Evaporation" in lake area change.

In general, given that precipitation and evaporation are the immediate factors of surface area changes for these urban lakes, the intra-annual seasonal lake change was largely caused by precipitation and evaporation. However, the impact of precipitation and evaporation on the seasonal fluctuation of lakes is often complex, as there are human activities impacts on the urban lakes. For example, the small fluctuation of lakes is mainly caused by the construction of lake embankment. For these lakes, although the precipitation had a big fluctuation, the water area would not be changed greatly unless the severe flood or drought. In all, most lakes showed a downward trend of area in the study period. Because of the steady trend lines of seasonal change of climatic factors and the upward trend line of annual impervious surface area, human activity is the more important driving variable influencing the long-term lake area change.

In order to analyse the relative importance of the driving variables that relate to the five-year permanent water disappearance, the correlation between the five-year 
permanent water area and the five-year precipitation accumulated anomalies as well as the five-year impervious surface area accumulated anomalies is shown in Figure 10. The $R^{2}$ between the impervious surface and the permanent lake area is 0.9175 which is greater than the $R^{2}$ between the "Precipitation minus Evaporation" and the permanent lake area. Given that the explanatory power of impervious surface to five-year permanent water change is $91.75 \%$ this suggests, although there are limitations to the analysis, that human activities are the main driving variables that relate to the permanent disappearance of water in Wuhan.
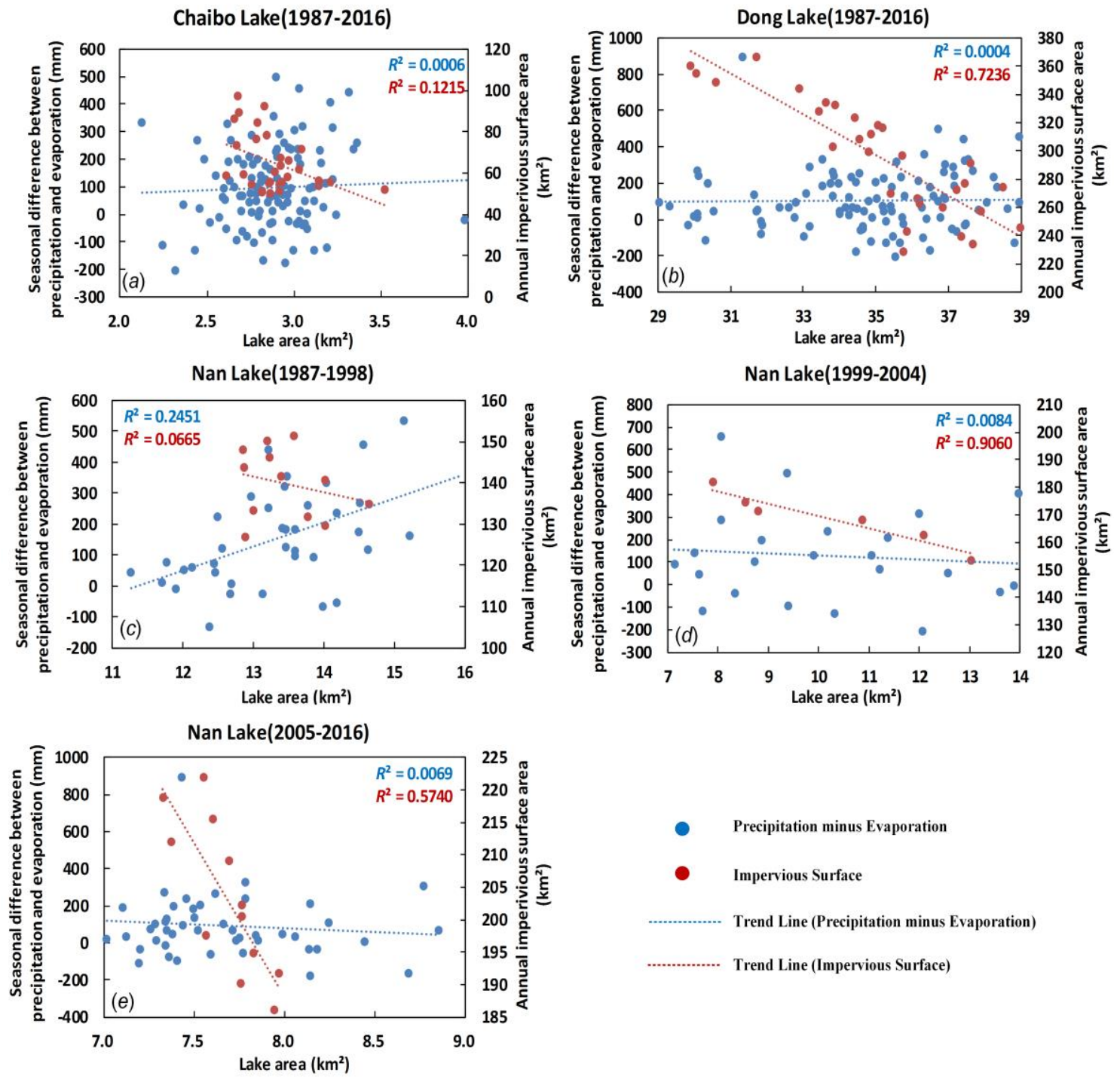

Figure 9. The relative importance of two driving variables of the lake area change. 


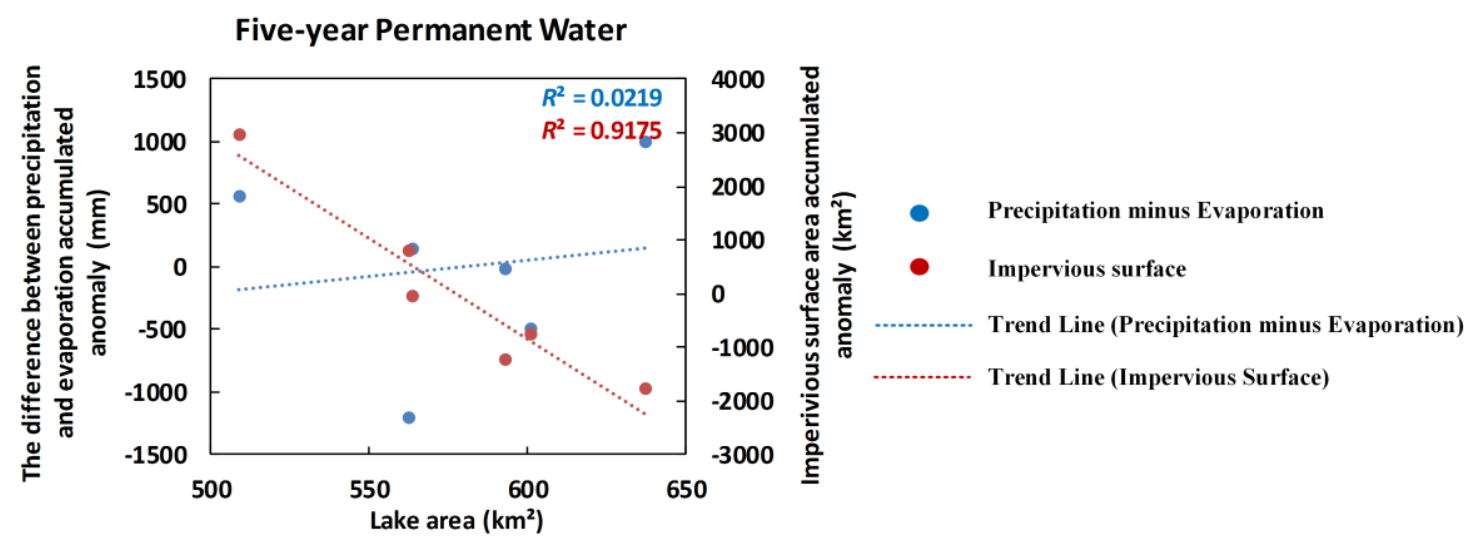

Figure 10. The relative importance of the two driving variables of five-year permanent water change

\section{Conclusions}

The spatio-temporal change of urban lakes in Wuhan was analysed using a long time series of remotely sensed images from 1897 to 2016. In terms of temporal change, the BFAST method was used to produce the trend line and abrupt time point of the long-term lake area change. In terms of spatial change, the frequency analysis was used to reflect the water area change in the whole Wuhan. In all, the seasonal change of lake area for 28 lakes was studied to explore the temporal change of urban lake areas. A series of water maps focused on five-year period were produced to reflect the spatial change of urban lakes. The results showed that most lakes in Wuhan had shrunk over the past 30 years resulting in a permanent change from water to land. The shrinkage was also most apparent in the central region of the city which reflected that the urban expansion model in Wuhan was from centre to the edge. Seasonal fluctuations of lake area were evident for most lakes but the relative important driving variables of lake area change varied between subperiods of time for different lakes because of the unbalance of urban expansion. $20.12 \%$ five-year permanent water in Wuhan disappeared from 1987 to 2016. The results suggest that increasing the impervious cover was the main variable impacting on lake change, suggesting that urbanization was the most important driving variable causing the 
shrinkage of urban lakes in Wuhan.

Although this study shows a long time series remote sensing imagery can provide valuable information on urban lake change, there is still uncertainty in the result. The latter is associated especially with three issues. First, the 16-day repeat cycle of Landsat data is not sufficient to provide data if we want to focus on a shorter time interval (e.g. every year) for water inundation frequency mapping. With the launch of more and more high spatial resolution and short revisit period satellites, a further enhancement to this study is improving the spatial resolution of lake mapping and temporal resolution of the water inundation frequency. Second, the accuracy of the water body mapping is affected by the quality of remotely sensed imagery used, such as the cloud and aquatic plants in lakes. A more powerful classification algorithm is also needed to extract the waterbodies accurately. Third, remote sensing still has some limits in representing the reality of lakes and their change in time and space. For example, means to address issues such as changes apparent caused by the construction of bridges over lakes are required to avoid misestimation of the lake area.

\section{Disclosure statement}

No potential conflict of interest was reported by the authors.

\section{Reference}

Belgiu, Mariana, and Lucian Drăguţ. 2016. "Random forest in remote sensing: A review of applications and future directions." Isprs Journal of Photogrammetry \& Remote Sensing 114:24-31.

Brown, Antony G., Keneth J. Gregory, and Edward J. Milton. 1987. "The use of Landsat multispectral scanner data for the analysis and management of flooding on the river Severn, England." Environmental Management 11 (5):695-701.

Byoung Chul, Ko, Kim Hyeong Hun, and Nam Jae Yeal. 2015. "Classification of Potential Waterbodies Using Landsat 8 OLI and a Combination of Two Boosted Random Forest Classifiers." Sensors 15 (6):13763-77.

Chander, Gyanesh, Brian L. Markham, and Dennis L. Helder. 2009. "Summary of current radiometric calibration coefficients for Landsat MSS, TM, ETM+, and EO-1 ALI sensors." Remote Sensing of Environment 113 (5):893-903. 
Dao, Phuong D., and Yuei An Liou. 2015. "Object-Based Flood Mapping and Affected Rice Field Estimation with Landsat 8 OLI and MODIS Data." Remote Sensing 7 (5):5077-97.

Deng, Yue, Weiguo Jiang, Zhenghong Tang, Jiahong Li, Jinxia Lv, Zheng Chen, and Kai Jia. 2017. "Spatio-Temporal Change of Lake Water Extent in Wuhan Urban Agglomeration Based on Landsat Images from 1987 to 2015." Remote Sensing 9 (3): 270 .

Du, Ningrui, Henk Ottens, and Richard Sliuzas. 2010. "Spatial impact of urban expansion on surface water bodies-A case study of Wuhan, China." Landscape \& Urban Planning 94 (3-4):175-85.

Du, Yun, Yihang Zhang, Feng Ling, Qunming Wang, Wenbo Li, and Xiaodong Li. 2016. "Water Bodies' Mapping from Sentinel-2 Imagery with Modified Normalized Difference Water Index at 10-m Spatial Resolution Produced by Sharpening the SWIR Band." Remote Sensing 354 (8):1-19.

Feng, Lian, Chuanmin Hu, Xiaoling Chen, Xiaobin Cai, Liqiao Tian, and Wenxia Gan. 2012. "Assessment of inundation changes of Poyang Lake using MODIS observations between 2000 and 2010." Remote Sensing of Environment 121 (2):80-92.

Feyisa, Gudina L., Henrik Meilby, Rasmus Fensholt, and Simon R. Proud. 2014. "Automated Water Extraction Index: A new technique for surface water mapping using Landsat imagery." Remote Sensing of Environment 140 (1):23-35.

Foody, Giles M. 2002. "Status of land cover classification accuracy assessment." Remote Sensing of Environment 80 (1):185-201.

Friedl, Mark A, and Carla E Brodley. 1997. "Decision tree classification of land cover from remotely sensed data." Remote Sensing of Environment 61 (3):399-409.

Gunn, Steve R. 1998. "Support vector machines for classification and regression." ISIS technical report 14 (1):5-16.

Halabisky, Meghan, L. Monika Moskal, Alan Gillespie, and Michael Hannam. 2016. "Reconstructing semi-arid wetland surface water dynamics through spectral mixture analysis of a time series of Landsat satellite images (1984-2011)." Remote Sensing of Environment 177:171-83.

Han, Xingxing, Xiaoling Chen, and Lian Feng. 2015. "Four decades of winter wetland changes in Poyang Lake based on Landsat observations between 1973 and 2013." Remote Sensing of Environment 156:426-37.

Hui, Fengming, Bing Xu, Huabing Huang, Qian Yu, and Peng Gong. 2008. "Modelling spatial-temporal change of Poyang Lake using multitemporal Landsat imagery." International Journal of Remote Sensing 29 (20):5767-84.

Ii, B. L. Turner. 2010. "The Earth as Transformed by Human Action." Professional Geographer 40 (3):340-1.

Ji, L, L Zhang, and B Wylie. 2009. "Analysis of dynamic thresholds for the normalized difference water index." Photogrammetric Engineering \& Remote Sensing 75 (11):1307-17.

Kai, Xu, Chun Fang Kong, Liu Gang, Chong Long Wu, Hong Bin Deng, Zhang Yi, and Q. L Zhuang. 2010. "Changes of urban wetlands in Wuhan, China, from 1987 to 2005." Progress in Physical Geography 34 (2):207-20.

Li, Wenbo, Zhiqiang Du, Feng Ling, Dongbo Zhou, Hailei Wang, Yuanmiao Gui, Bingyu Sun, and Xiaoming Zhang. 2013. "A Comparison of Land Surface Water Mapping Using the Normalized Difference Water Index from TM, ETM+ and ALI." Remote Sensing 5 (11):5530-49. 
Li, Wenbo, Xiuhua Zhang, Feng Ling, and Dongbo Zheng. 2016. "Locally adaptive super-resolution waterline mapping with MODIS imagery." Remote Sensing Letters 7 (12):1121-30.

Liaw, Andy, and Matthew Wiener. 2002. "Classification and regression by randomForest." $R$ news 2 (3):18-22.

Lobo, Felipe L., Maycira P. F. Costa, and Evlyn M. L. M. Novo. 2015. "Time-series analysis of Landsat-MSS/TM/OLI images over Amazonian waters impacted by gold mining activities." Remote Sensing of Environment 157:170-84.

Mcfeeters, S. K. 1996. "The use of the Normalized Difference Water Index (NDWI) in the delineation of open water features." International Journal of Remote Sensing 17 (7):1425-32.

Moknatian, Mahrokh, Michael Piasecki, and Jorge Gonzalez. 2017. "Development of Geospatial and Temporal Characteristics for Hispaniola's Lake Azuei and Enriquillo Using Landsat Imagery." Remote Sensing 9 (6):510.

Mueller, N., A. Lewis, D. Roberts, S. Ring, R. Melrose, J. Sixsmith, L. Lymburner, A. Mcintyre, P. Tan, and S. Curnow. 2016. "Water observations from space: Mapping surface water from 25 years of Landsat imagery across Australia." Remote Sensing of Environment 174:341-52.

Ozesmi, Stacy L., and Marvin E. Bauer. 2002. "Satellite Remote Sensing of Wetlands." Wetlands Ecology \& Management 10 (5):381-402.

Pantaleoni, E, R. H Wynne, J. M Galbraith, and J. B Campbell. 2009. "Mapping wetlands using ASTER data: a comparison between classification trees and logistic regression." International Journal of Remote Sensing 30 (13):3423-40.

Pekel, J. F., A. Cottam, N. Gorelick, and A. S. Belward. 2016. "High-resolution mapping of global surface water and its long-term changes." Nature 540 (7633):418-22.

Rokni, Komeil, Anuar Ahmad, Ali Selamat, and Sharifeh Hazini. 2014. "Water Feature Extraction and Change Detection Using Multitemporal Landsat Imagery." Remote Sensing 6 (5):4173-89.

Schneider, A., and C M Mertes. 2014. "Expansion and growth in Chinese cities, 19782010." Environmental Research Letters 9 (2):024008.

Shi, Lingfei, Feng Ling, Yong Ge, Giles M Foody, Xiaodong Li, Lihui Wang, Yihang Zhang, and Yun Du. 2017. "Impervious surface change mapping with an uncertainty-based spatial-temporal consistency model: A case study in wuhan city using landsat time-series datasets from 1987 to 2016." Remote Sensing 9 (11): 1148 .

Smith, Jonathan H, Stephen V Stehman, James D Wickham, and Limin Yang. 2003. "Effects of landscape characteristics on land-cover class accuracy." Remote Sensing of Environment 84 (3):342-9.

Strahler, Alan H. 1980. "The use of prior probabilities in maximum likelihood classification of remotely sensed data." Remote Sensing of Environment 10 (2):135-63.

Tulbure, Mirela G., and Mark Broich. 2013. "Spatiotemporal dynamic of surface waterbodies using Landsat time-series data from 1999 to 2011." Isprs Journal of Photogrammetry \& Remote Sensing 79 (330):44-52.

Tulbure, Mirela G., Mark Broich, Stephen V. Stehman, and Anil Kommareddy. 2016. "Surface water extent dynamics from three decades of seasonally continuous Landsat time series at subcontinental scale in a semi-arid region." Remote Sensing of Environment 178:142-57. doi: 10.1016/j.rse.2016.02.034. 
Verbesselt, Jan, Rob Hyndman, Glenn Newnham, and Darius Culvenor. 2010. "Detecting trend and seasonal changes in satellite image time series." Remote Sensing of Environment 114 (1):106-15.

Vitousek, Peter M., Harold A. Mooney, Jane Lubchenco, and Jerry M. Melillo. 1997. "Human Domination of Earth's Ecosystems." Science 277 (5325):494-9.

Wang, Wenfeng, Anne Wairimu Ndungu, Zhen Li, and Jun Wang. 2017. "Microplastics pollution in inland freshwaters of China: a case study in urban surface waters of Wuhan, China." Science of the Total Environment 575:1369-74.

Wang, Xia, Yaolin Liu, Feng Ling, and Shuna Xu. 2018. "Fine spatial resolution coastline extraction from Landsat-8 OLI imagery by integrating downscaling and pansharpening approaches." Remote Sensing Letters 9 (4):314-23.

$\mathrm{Xu}$, Hanqiu. 2006. "Modification of normalised difference water index (NDWI) to enhance open water features in remotely sensed imagery." International Journal of Remote Sensing 27 (14):3025-33.

Yang, Bohan, and Xinli Ke. 2015. "Analysis on urban lake change during rapid urbanization using a synergistic approach: A case study of Wuhan, China." Physics \& Chemistry of the Earth Parts A/b/c 89-90:127-35.

Yang, Yuhao, Yongxue Liu, Minxi Zhou, Siyu Zhang, Wenfeng Zhan, Chao Sun, and Yuewei Duan. 2015. "Landsat 8 OLI image based terrestrial water extraction from heterogeneous backgrounds using a reflectance homogenization approach." Remote Sensing of Environment 171:14-32.

Yun, Du, Xue Huai-Ping, Wu Sheng-Jun, Ling Feng, Xiao Fei, and Wei Xian-Hu. 2011. "Lake area changes in the middle Yangtze region of China over the 20th century." Journal of Environmental Management 92 (4):1248-55. 